\title{
DROUGHT HAZARD CHARACTERISTIC USING SOIL MOISTURE DEFICIT INDEX MODELLING
}

\author{
L. M. Fitria ${ }^{a}$, S. Fathurrohmah ${ }^{\text {a }}$ \\ a Urban and Regional Planning Department, Sekolah Tinggi Teknologi Nasional Yogyakarta, SMN, 55281, Indonesia
}

\section{Article Info:}

Received: 2 August 2017

in revised form: 1 January 2018

Accepted: 30 March 2018

Available Online: 25 April 2018

\section{Keywords:}

Drought, hazard, modelling, soil moisture, GIS

\section{Corresponding Author:}

Lulu Mari Fitria

Urban and Regional Planning Department, Sekolah Tinggi

Teknologi Nasional Yogyakarta,

Sleman, Indonesia

Email: lulumari@sttnas.ac.id

\begin{abstract}
Drought happen when the rainfall decreases in the extreme condition for long period of time (above normal). Drought hazard mapping can be analyzed by various approaches, like environmental approach, ecological approach, hydrological approach, meteorological approach, geological approach, agricultural approach, and many other. Badan Meteoroligi dan Geofisika (BMKG) measures the drought hazard by utilizing Standardized Precipitation Index (SPI)The comparison of rainfall rate through SPI has positive correlation with drought type, for example SPI 3 indicates agricultural drought; while SPI 6, SPI 9 and SPI 12 indicate hydrological drought. The analysis of drought hazard level also can be done using soil moisture level measurement. Soil moisture is the result of water shortages in the hydroclimatological concept. Soil moisture analysis utilizes several influenced variables, such as soil water, precipitation, evapotranspiration, and percolation. Each of variables was analyzed using GIS Software as a method of soil moisture modeling. Drought index level analysis is using soil moisture deficit index, which indicates that drought occurs if the index score less than $(-0,5)$. Some assumptions used in this modeling are both SMDI modeling using WHC (Water Holding Capacity) and without using WHC. This modeling used medium term analysis during 2007-2012 to prove the occurrence of extreme drought on 2009 and 2012 for measurement of drought level in agriculture area. Based on SMDI, it is known that the dangers of SMDI drought have positive correlation to SPI 3, SPI 6, SPI 9, and SPI 12, where SPI is in accordance with the interpretation of meteorolgy, agriculture, and hydrological drought indices.
\end{abstract}

Copyright (C) 2018 GJGP-UNDIP This open access article is distributed under a Creative Commons Attribution (CC-BY-NC-SA) 4.0 International license.

How to cite (APA 6th style): Fitria, L.M. \& Fathurrohmah, S. (2018). Drought Hazard Characteristic Using Soil Moisture Deficit Index Modelling. Geoplanning: Journal of Geomatics and Planning, 5(1), 91-100. doi:10.14710/geoplanning. 5.1. 91-100

\section{INTRODUCTION}

Drought was triggered by the extreme decreasing level of rainfall. In a certain period, drought became worse which is impact of human life (Huang et al., 2017; Miller \& Fox, 2017; Zolotokrylin, 2010). Decreasing of rainfall in below average were the main trigger of drought which can be aggravated by the presence of climate change, land use change and degradation of environment (Huang et al., 2017; Thomas at al., 2014). Drought disaster provides economic, social, environment and ecological losses, such as decreasing quality of life, decreasing agricultural production which may lead to crop failures, forest fires, environmental degradation and desertification, etc (Zin et al., 2012; Hao et al., 2017; Huang et al., 2017). Drought prone areas are usually more widespread than other natural disasters that can impact global, continental, regional and local levels with different durations of drought events (Huang et al., 2017; Ma et al., 2015; Thomas et al., 2014; Wilhelmi \& Wilhite, 2002).

Climate, soil, and water supply are the variables used in analyzing drought (Thomas et al., 2014). Drought can be indicated by decreasing level of soil water, decreasing level of water discharge in rivers, dams, and groundwater. There are four types of drought, wich are meteorological drought, agriculture drought, hydrology drought and socioeconomic drought (Hao et al., 2017; Lu et al., 2017; Thomas et al., 2014; Wilhelmi \& Wilhite, 2002). Drought meteorology is a drought characterized by the decreasing level of rainfall below the normal average. The low rainfall coupled with the air temperature causes a decrease in soil moisture. Decrease in soil moisture is an indicator of agricultural drought. Hydrological drought occurs when there is a decreasing level of surface water discharge, such as decreasing level of water discharge in 
rivers, lakes / reservoirs. This low surface water discharge leads to a lack of water availability to meet water demand at household, industry, and others (Nagarajan, 2009; Thomas et al., 2014).

Drought hazard assessment was done by many researchers with various method. There are several methods can be utilized to examine the drought hazard, such as long-term period rainfall simulation, soil moisture simulation, and run off simulation (Ma et al., 2015). Moreover, there are several drought indexes which can be utilized to classified drought level, such as Agricultural Drought Intensity Index (ADI) (Lu et al., 2017); Multi-satellite Remote Sensing, Reanalysis, and Land Surface Model (Agutu et al., 2017); Standardized streamflow index (SSI) (Huang et al., 2017); Soil Moisture Deficit Index in agricultural area (Narasimhan \& Srinivasan, 2003;Tessema, 2007); Stream Flow Record (Miller \& Fox, 2017); Reconnaissance Drought Index (RDI) (Tsakiris et al., 2006), etc. Among those afore mentioned method, analysis using rainfall data through Standarized precipitation index (SPI) is the most utilized method (Livada \& Assimakopoulos, 2006; Zin et al., 2012). In Indonesia, SPI was used as a standard of drought index by Meteorological, Climatological and Geophysical agency (Badan Meteorologi, Klimatologi, dan Geofisika/ BMKG). In addition, the researchers used SPI as a validation method in testing drought hazard models (Agutu et al., 2017; Hao et al., 2017; Huang et al., 2017; Lu et al., 2017; Manatsa et al., 2010).

Soil Moisture Deficit Index (SMDI) measurements can be used as an indicator of agricultural drought (Nagarajan, 2009; Narasimhan \& Srinivasan, 2003; Tessema, 2007). Previous research has demonstrated the uses of SMDI model by utilizing Soil Water Assessment Tools (SWAT). In this study, SMDI model was established by utilizing soil water model with evapotranspiration, and percolation as a variable. The Standarized Precipitation Index (SPI) was used as a validation of the SMDI model to obtain drought hazard mapping (Narasimhan \& Srinivasan, 2003; Tessema, 2007). Geographic Information System (GIS) is used as a tool to perform analysis in this research.

The objective of this research is (1) to build drought indicator measurement model through soil moisture deficit index by using GIS; (2) to identify the characteristics of SMDI by using SPI. This study provides an overview of techniques in building models through GIS to map drought prone area. The results of this study can be used as an alternative in the determination of drought-prone areas, so it can contributes to disaster mitigation as well as in regional planning.

\section{DATA AND METHODS}

\subsection{Study Site}

This research was conducted in Purworejo Sub-district, Purworejo District, Central Java Province. This research was conducted in villages prone to drought in Purworejo Sub-district covering 9 villages in Brenggong, Cangkrep Kidul, Ganggeng, Plipir, Pacekelan, Sidorejo, Sidomulyo, Donorati and Wonotulus villages (Figure 1). Those villages are the part of the Bogowonto River Basin. This research focused on agricultural areas as they relate to the measurement of soil moisture.

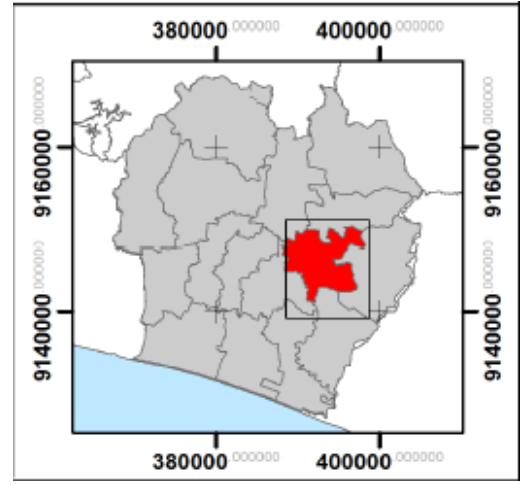

Purworejo District

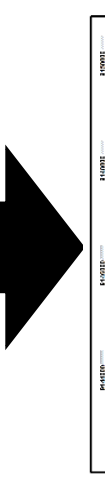

Drought Prone Area

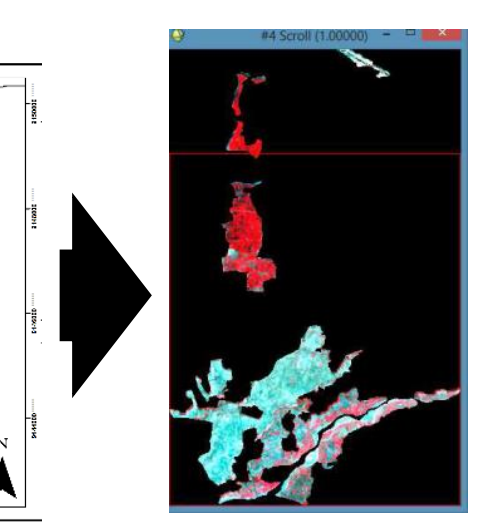

Planting Area

Figure 1. Study Site drought prone area Purworejo District, Purworejo Regency, Central Java, Indonesia 


\subsection{Data Set}

This research utilizes several types of data, including aster, meteorological, climatology, physical data and crop yields data. In order to investigate the climate variability, 23 years of continuous data from five meteorological stations in this area were selected to generated rainfall characteristic. The stations are located in around agriculture areas. The model was established by utilizing the daily meteorological and climatological data from 2007 - 2012. The climatological and meteorological data were collected from BPDASSOP (Watershed Management Center Serayu Opak Progo). The variables of climatological includes temperature, humidity, solar radiation, wind speed, and precipitation.

Agricultural data was generated from Aster satellite imagery to detect crops in yield field. The data regarding crops types were obtained by utilizing normalized difference vegetation index (NDVI) method. The NDVI formula can be denoted as:

$$
N D V I=\left(\frac{N I R-R E D}{N I R+R E D}\right)
$$
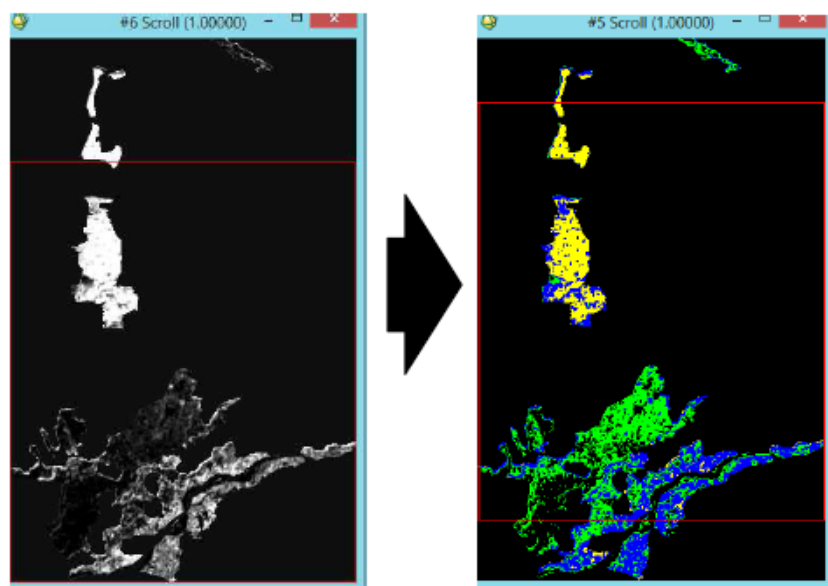

Figure 2. NDVI Analysis

The result of NDVI analysis (Figure 2) were classified into four classes based on its density (Wahyunto \& Heryanto, 2006). The classification was validated by conducting interview to several stakeholders. The crop types in study area are paddy and tobacco. The agricultural data include planting area, crop yield, and crop types. Physical data includes soil type and soil texture. Soil types were collected from BPDASSOP (Watershed Management Center Serayu Opak Progo). Texture soil were collected from field survey and laboratory test.

\subsection{Methodology}

\subsubsection{Soil Moisture Deficit Index}

The drought hazard indicator is defined as the ratio of the area affected by drought. Model were used in drought hazard indicator by Soil Moisture Modeling. Soil Moisture Modeling were generated by soil water model. SMDI model were built by Narasimhan \& Srinivasan (2003) using Soil Water Analysis Tools (SWAT) then developed by Tessema (2007) by using monthly model. In this study, SMDI Model were analyzed using GIS by soil water (SW).

(a) Soil Water (SW)

Soil water model were used to SMDI analysis. SW model consists of precipitation, evapotranspiration, and percolation variables. The formula of SWB are:

$\mathrm{SW}_{\mathrm{t}}=\mathrm{SW}_{\mathrm{t}}-1+(\mathrm{P}-\mathrm{ETa}-$ Perc $)$

where $\mathrm{SW}_{\mathrm{t}}$ is soil water $(\mathrm{mm})$; $\mathrm{P}$ is precipitation $(\mathrm{mm} / \mathrm{month})$; Eta is actual evapotranspiration $(\mathrm{mm} / \mathrm{month})$; Perc is percolation ( $\mathrm{mm} /$ month); $\mathrm{t}$ is time (month)

i. Precipitation

Precipitation data used in this study is monthly rainfall collected from each rainfall stations for 23 years. The precipitation data in SW analysis was daily rainfall during the period of $2007-$ 2012. 
ii. Evapotranspiration

Actual evapotranspiration is formulated by Blaney-Criddle model. The formula of actual evapotranspiration is:

$E T a=k c^{*} E T o=k c *(a+b(p(0,46 t+8,13)))$

Where Eta is actual evapotranspiration; ETo is potential evapotranspiration; Kc is Crop coefficient; $p$ is average of daily sun in a year; $t$ is average daily temperature; $a, b$ is Constanta of humidity, wind speed, and solar radiation.

iii. Percolation

Percolation standard were collected by Besrean River Japan, Rice Irrigation in Japan OTCA (1973). The percolation standard was classified by soil texture. The percolation classes are:
a. Sandy loam : $3-6 \mathrm{~mm} /$ day
b. Loam $\quad: 2-3 \mathrm{~mm} / \mathrm{day}$
c. Clay loam $: 1-2 \mathrm{~mm} /$ day

(b) SMDI

SMDI was generated by Soil Water formula for generated soil water deficit. Tessema (2007) was use monthly model to generate soil deficit. The formula of soil deficit (SD) are :

$$
\begin{array}{ll}
S D_{i, j}=\frac{S W_{i, j}-M S W_{j}}{M S W_{j}-\operatorname{minSW}_{j}} \times 100 & \text { jika } S W \leq M S W \\
S D_{i, j}=\frac{S W_{i, j}-M S W_{j}}{M a x S W_{j}-M S W_{j}} \times 100 & \text { jika } S W>M S W
\end{array}
$$

where $\mathrm{SD}_{\mathrm{ij}}$ is percentage of water deficit (\%); $S W_{\mathrm{ij}}$ is monthly average of soil water $(\mathrm{mm})$; $\mathrm{MSWj}$ is median of soil water $(\mathrm{mm})$; Max.SW $\mathrm{W}_{\mathrm{j}}$ is maximum of soil water $(\mathrm{mm})$; Min.SW $\mathrm{W}_{\mathrm{j}}$ is minimum of soil water $(\mathrm{mm})$; $\mathrm{i}$ is long period; $\mathrm{j}$ is monthly period.

Drought hazard modeling were generated by SMDI with two assumptions, they are SMDI I and SMDI II. SMDI assumptions are described by SW analysis both without Water Holding Capacity and with Water Holding Capacity. The SMDI II uses WHC assumption (Moeletsi \& Walker, 2012) if SW> WHC, $S W=W H C$; if $S W<0, S W=0$. The $S M D I$ formulas are:

$$
\begin{aligned}
& S M D I_{1}=S M D I_{0}=S M D I_{1}=\frac{S D_{1}}{50} ; \\
& S M D I_{j}=0,5 S M D I_{j-1}+\frac{S D_{j}}{50}
\end{aligned}
$$

where SMDI is Soil Moisture Deficit Index; $\sum_{t=1}^{j} S D_{t}$ is amount of soil water deficit each month.

\subsubsection{Standardized Precipitation Index}

BMKG uses SPI as drought indicator in Indonesia. In this study, SPI was used to validate SMDI model. SPI was generated from the long term rainfall data collected on each station. The formula of SPI are:

$$
\mathrm{SPI}=\frac{X_{i}-X_{m}}{\sigma}
$$

In which SPI is Standardized Precipitation Index; $\mathrm{Xi}$ is monthly rainfall; $\mathrm{Xm}$ is average rainfall; and $\sigma$ is standard deviation.

\subsubsection{Correlation}

Correlation analysis was used to compare SMDI model and SPI analysis. Correlation analysis was conducted using SPSS Software. The correlation between variables is indicated by the significance level of 0.01 .

\section{RESULT AND DISCUSSION}

\subsection{Soil Moisture Deficit Index Modeling}

In this study, SMDI modeling was analyzed using two assumptions which are without WHC and with WHC in 2007 - 2012. SMDI I model is established without WHC (Narasimhan \& Srinivasan, 2003) while 
SMDI II is established with WHC (Thornthwaite \& Mather, 1957). The result of SMDI I for 5 years is fluctuated. SMDI analysis was conducted to determine the level of drought index in the study area. Graph below shows the plots of SMDI I:

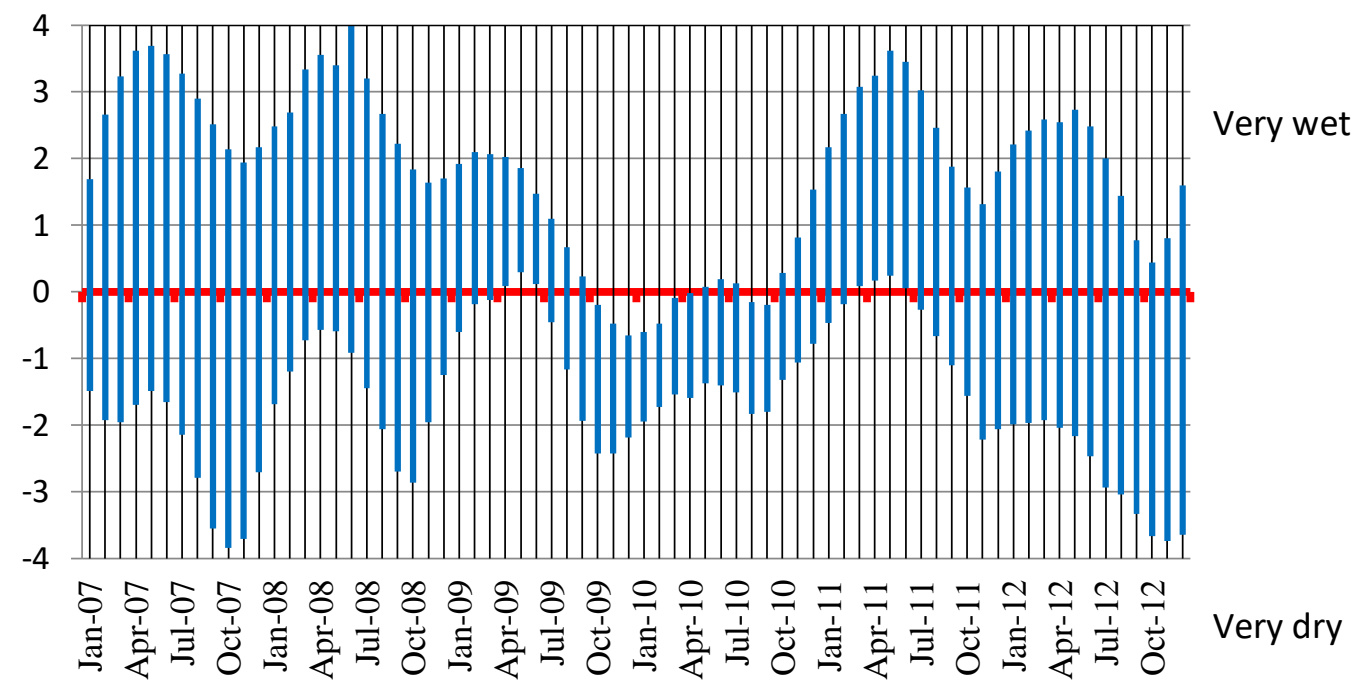

Figure 3. Graph of SMDI I on 2007 - 2012 (Analysis, 2014)

Figure 3 shows the fluctuation of dryness index of SMDI I calculation during 2007 - 2012. It is known that the variation of drought level in the research area is very diverse. In 2009, the drought level in research area has a short range between -1 to -3 . It means that all areas was experiencing drought inequal level. Based on the data from NOAA monitoring (2014), it is known that August 2009 - May 2010 is the period of El Nino, which caused the rise of sea level and drought on the land. Based on dry month analysis, it is also known that during June - December 2009 the rainfall level in the study area was below normal. In August 2012 it was found that extreme drought occurred with index $(-3)$, but the range variation of index is between (-3) - 1 which means that not all regions experiencing drought. Furthermore, figure 4 shows the standard deviation of SMDI analysis using GIS:

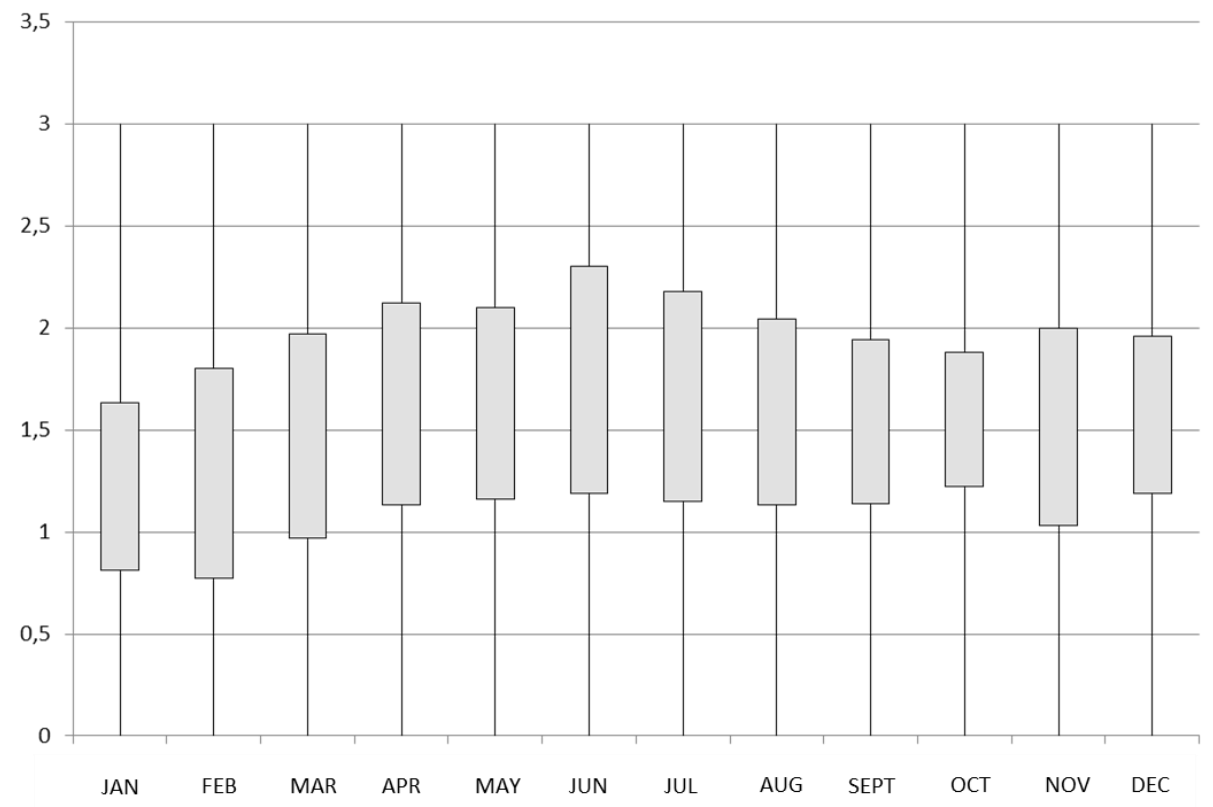

Figure 4. Standard Deviation of SMDI I (Analysis, 2014)

Figure 4 shows that the highest standard deviation range occurs in June, with an average of 1.745 . This is due to the beginning of the dry season so that the variation of data distribution is large. Meanwhile in January, the average standard deviation is $\mathbf{1 . 2 2}$. This means that the data distribution is almost similar. 
January is the rainfall periods thus the variation of its SMDI data is almost similar. It is also mentioned by Narasimhan (2003) that in dry season, the value of SMDI standard deviation increases. This is caused by the spatial variation of decreased rainfall and land use, in the term of vegetation type and age. Otherwise, in the rainy season, value of SDMI spatial variation decreases. This is due to high rainfall and soil will be filled by water, so that spatial variation of SMDI decreases.

In the analysis of SMDI II, the value considers about WHC that is in SW calculation calculated based on mean value as the normal value assumption of soil moisture. Figure 5 shows the value of SDMI II:

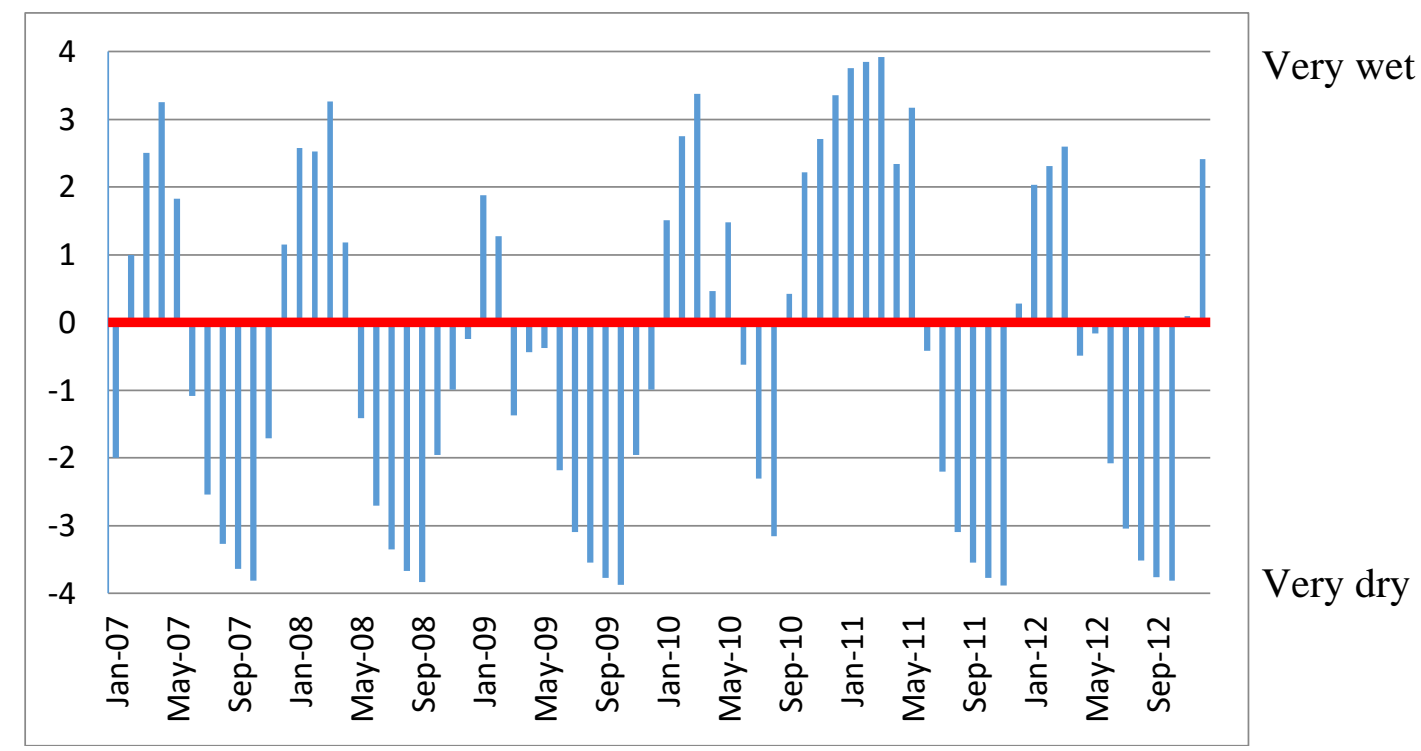

Figure 5. Standard Deviation of SDMI II (Analysis, 2014)

Figure 5 shows that the average value of SMDI II is below 0 in May and June. However, in 2009 and 2012 the value of SMDI II fell below 0 in March and April. The result indicates that the drought in 2009 and 2012 began in March and April and increased again in November and December. Narasimhan (2003) analyzed SMDI based on soil depth by dividing it into 3 levels, which are at depths of $2 \mathrm{ft}, 4 \mathrm{ft}$ and $6 \mathrm{ft}$. In this analysis, soil depth is calculated from the depth of plant roots on each soil texture. According to Narasimhan (2003), this research of SMDI II analysis at $2 \mathrm{ft}$ level because soil depth at SMDI II is about 0.25 $0.62 \mathrm{~m}$. Based on the figure above, the value of SMDI II is very fluctuative. It is caused by the conditions of soil profile which is very active against evapotranspiration of SW conditions (Narasimhan, 2003). The value of withered point for each soil texture varies. The permanent withered point is situation where the plant withered due to lack of water in soil. Although soil still can store water, but plant is unable to extract water from soil (Nagarajan, 2009). Therefore, when $S W<0$ then $S W=$ Obecause it has exceeded to the point of permanent wither. When $S W \geq W H C$ then $S W=W H C$, because the excess water will be run off and percolation.

\subsection{Drought Characteristic}

\subsubsection{Standardized Precipitation Index}

The SPI analysis was performed as a comparison for SMDI validation using correlation analysis between SMDI and SPI. This was done because the analysis of SPI 3, SPI 6, SPI 9, and SPI 12 have positive correlation with the calculation of drought index (Sivakumar, 2011). SPI 3 is suitable to interpret agricultural drought index based on conditions of soil moisture at short and medium term. This is because SPI 3 compares the 3rd month rainfall compared with the total rainfall from the previous 3 months for a year. Whereas, SPI 6, 9 and 12 are suitable to interpret hydrological drought index. This hydrological drought is indicated by reservoir level, river discharge, and groundwater level. 


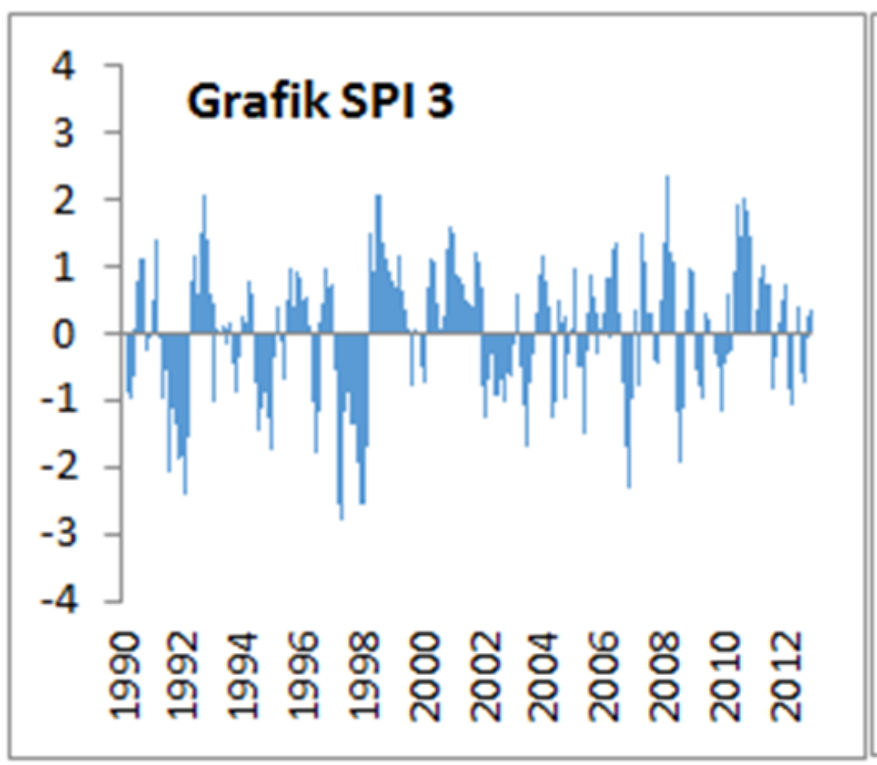

(a)

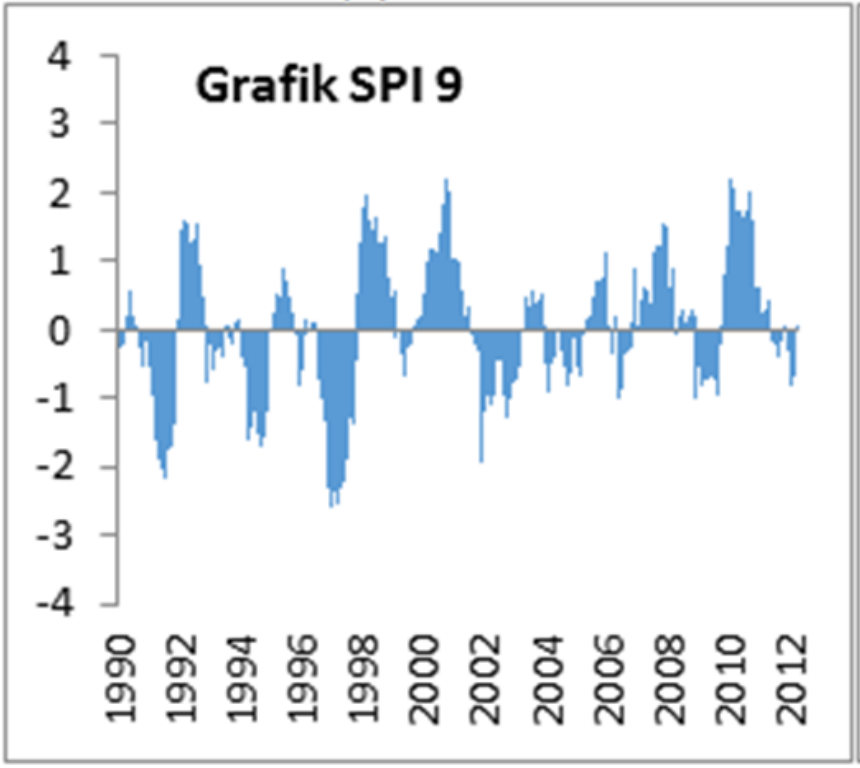

(c)

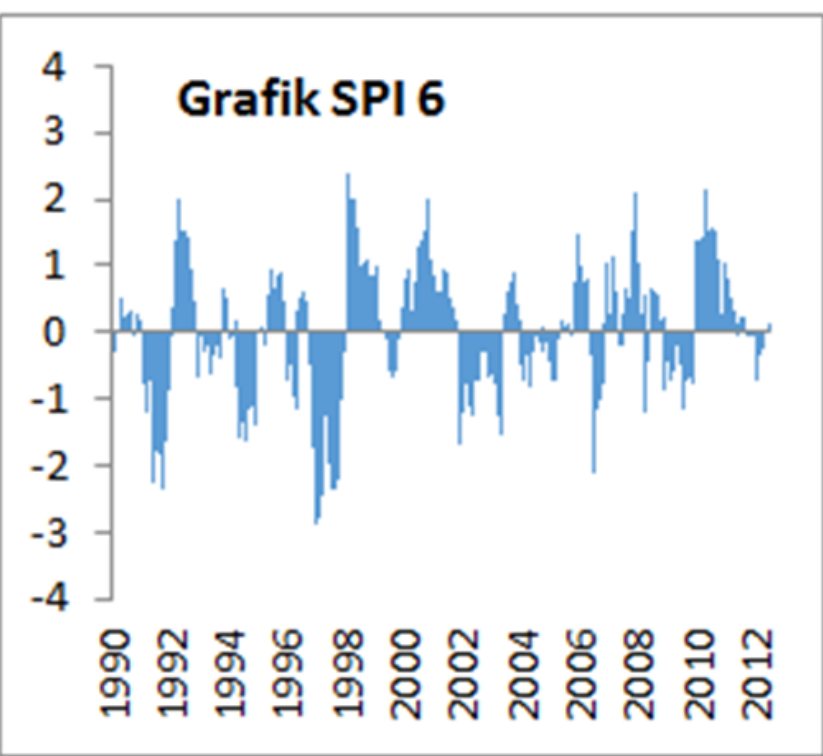

(b)

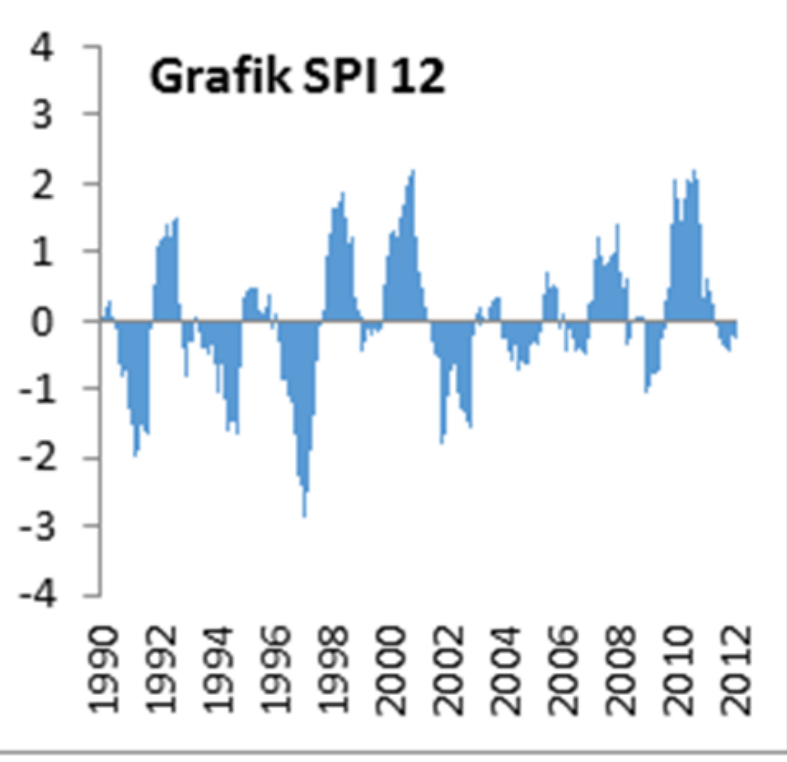

(d)

Figure 6. (a) SPI 3; (b) SPI 6; (c) SPI 9; (d) SPI 12 (Analysis, 2014)

Based on Figure 6, SPI 3 is fluctuative. It is influenced by some reason that SPI 3 well-used for short and medium term drought index because it is affected by rainfall in 3 month period. Whereas in SPI 6, 9, and 12 have fairly clear drought index value, ie, drought occurred in 2009 and 2012 with a dryness index below 0.

\subsubsection{Drought Characteristic}

Correlation analysis was performed to validate the previous SMDI model using GIS analysis to identify correlation between SMDI and SPI dryness index. Based on previous SMDI analysis, the average SMDI score is correlated with SPI analysis. The results of SMDI analysis were validated by correlating SMDI I and II with SPI 3,6,9, and 12. The result of correlation analysis is performed in the Table 1. 
Table 1. Correlation of SPI and AMDI (Analysis, 2014)

\begin{tabular}{|c|c|c|c|c|c|}
\hline \multicolumn{6}{|c|}{ Correlations } \\
\hline & & SPI3 & SPI6 & SPI9 & SPI12 \\
\hline \multirow[t]{3}{*}{ SMDI I } & Pearson Correlation & .132 & $.369^{* *}$ & $.463^{* *}$ & $.530^{* *}$ \\
\hline & Sig. (2-tailed) & .269 & .001 & .000 & .000 \\
\hline & $N$ & 72 & 72 & 72 & 72 \\
\hline \multirow[t]{3}{*}{ SMDI II } & Pearson Correlation & $.447^{* *}$ & .276 & 219 & 252 \\
\hline & Sig. (2-tailed) & .000 & .019 & .064 & .033 \\
\hline & $\mathrm{N}$ & 72 & 72 & 72 & 72 \\
\hline
\end{tabular}

= correlated

Table 1 shows that SMDI I has a correlation with SPI 6, 9, and 12. Thismeans that SMDI I can be used as indicator of hydrological drought. Otherwise, SMDI II has a correlation with SPI 3. This means that SMDI II can be used as indicator of medium-term drought or agricultural drought.
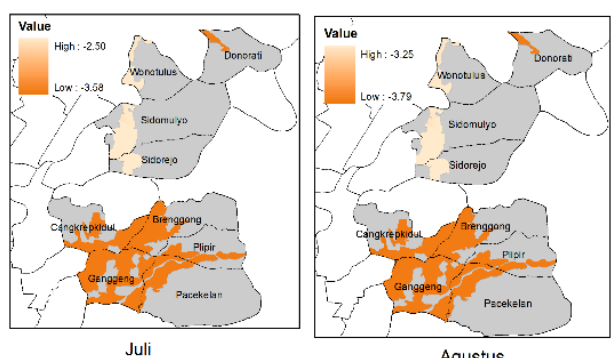

Aaustus

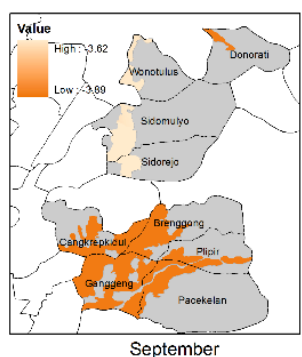

(a)

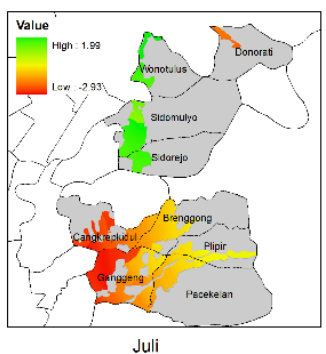

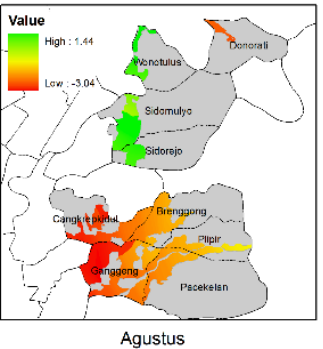

Agustus
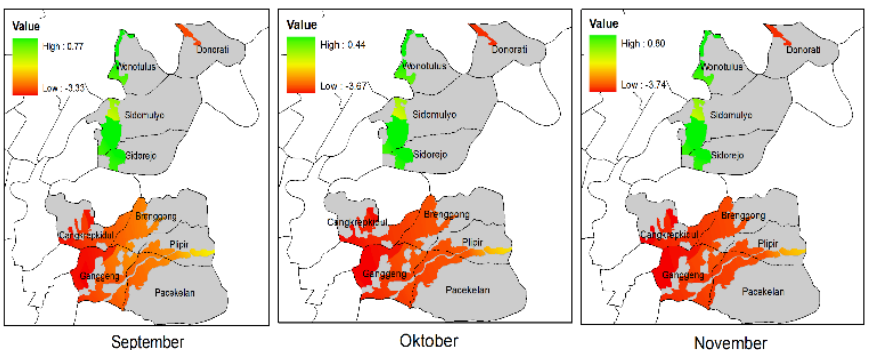

(b)

Figure 7. (a) SMDI II; (b) SMDI I

Based on Figure 7, SMDI II in 2012 is below 0 when agricultural drought occurred in July-October. In November, the value of SMDI II was above 0 where soil moisture in agricultural area has been normal again. Meanwhile, some regions have experienced hydrological drought in July. The drought in July increased until October but those range level of drought decreased. In November, SMDI begins to increase, but the rainfall has not been able to overcome the hydrological drought. This happens because hydrological drought includes reduction of water discharge in the rivers, reservoirs, and ground water. Positive correlation with a strong value in SMDI I and SPI 12 means that level of hydrological drought is based on rainfall comparison for 12 months period.

\section{CONCLUSION}

This study focused on presenting a framework of methodologies for the analysis of Soil Moisture Deficit Index Model using GIS to generate characteristics of agricultural droughts and hydrologic drought. We 
noted through the SMDI analysis of five station time series for the month of $2007-2012$ that relatively strong spatial and SPI station rainfall relationship prevails. This research come into conclusions that, the agricultural drought characteristic is correlated between SPI 3 and SMDI II. Meanwhile the hydrological drought characteristic is correlated between SPI 6, 9, 12 and SMDI I.

The result indicated that agricultural drought can be normalized if the level of rainfall increases in two months. In hydrological drought, increasing of the rainfall level cannot normalizes the drought in two months, especially in ground water level. It needs several period of times to normalize the hydrological drought.

\section{ACKNOWLEDGMENTS}

The study was supported by Gadjah Mada University, especially to Prof. Dr. H. A. Sudibyakto, M.S, Prof. Dr. rer. Nat. Muh. Aris Marfai, M.Sc., Prof. Dr. Hartono, DEA., DESS, Dr. M. Pramono Hadi, M.Sc. The Indonesian Ministry of Research, Technology, and Higher Education was supporting the research scholarship. Sekolah Tinggi Teknologi Nasional was a sponsorship.

\section{REFERENCES}

Agutu, N. O. et al. (2017). Assessing multi-satellite remote sensing, reanalysis, and land surface models products in characterizing agricultural drought in East Africa. Remote Sensing of Environment, 194, pp. 287-302. [Crossref]

Hao, Z. et al. (2017). An integrated package for drought monitoring, prediction and analysis to aid drought modeling and assessment. Environmental Modelling \& Software, 91, pp. 199-209. [Crossref]

Huang, S. et al. (2017). The propagation from meteorological to hydrological drought and its potential influence factors. Journal of Hydrology, 547, pp. 184-195. [Crossref]

Livada, I. and Assimakopoulos, V. D. (2006). Spatial and temporal analysis of drought in greece using the Standardized Precipitation Index (SPI). Theoretical and Applied Climatology. Springer Nature, 89(34), pp. 143-153. [Crossref]

Lu, H. et al. (2017). Effects of meteorological droughts on agricultural water resources in southern China. Journal of Hydrology, 548, pp. 419-435. [Crossref]

Ma, M. et al. (2015). Hydrologic model-based Palmer indices for drought characterization in the Yellow River basin, China. Stochastic Environmental Research and Risk Assessment. Springer Nature, 30(5), pp. 1401-1420. [Crossref]

Manatsa, D. et al. (2010). Analysis of multidimensional aspects of agricultural droughts in Zimbabwe using the Standardized Precipitation Index (SPI). Theoretical and Applied Climatology. Springer Nature, 102(3-4), pp. 287-305. [Crossref]

Miller, R. B. and Fox, G. A. (2017). A tool for drought planning in Oklahoma: Estimating and using droughtinfluenced flow exceedance curves. Journal of Hydrology: Regional Studies, 10, pp. 35-46. [Crossref]

Moeletsi, M. E. and Walker, S. (2012). Assessment of agricultural drought using a simple water balance model in the Free State Province of South Africa. Theoretical and applied climatology. Springer, 108(3-4), pp. 425-450.

Nagarajan, R. (2009). Drought Indices, in Drought Assessment. Springer Netherlands, pp. 160-204. [Crossref]

Narasimhan, B. and Srinivasan, R. (2003). Developing an Agricultural Drought Assessment System Using Hydrologic Model SWAT and GIS in 2003, Las Vegas, American Society of Agricultural and Biological Engineers, NV July 27-30, 2003. [Crossref]

Nasir, M. (no date). Deteksi Usia Tanaman Padi Berdasarkan Indeks Warna. .

Sivakumar, M. V. K. (2011). Agricultural drought-WMO perspectives, in Agricultural drought indices proceedings of an expert meeting, p. 24.

Tessema, R. S. (2007). Agricultural Drought Assessment for Upper Blue Nile Basin, Ethiopia using SWAT. Unesco-IHE.

Thomas, T. et al. (2014). Comprehensive evaluation of the changing drought characteristics in Bundelkhand region of Central India. Meteorology and Atmospheric Physics. Springer Nature, 127(2), pp. 163-182. [Crossref] 
Thornthwaite, C. W. and Mather, J. R. (1957). New Jersey Water Supply Development. Journal - American Water Works Association. Wiley, 49(8), pp. 969-985. [Crossref]

Tsakiris, G., Pangalou, D. and Vangelis, H. (2006). Regional Drought Assessment Based on the Reconnaissance Drought Index (RDI). Water Resources Management. Springer Nature, 21(5), pp. 821-833. [Cossref]

Wahyunto, W. and Heryanto, B. (2006). Pendugaan produktivitas tanaman padi sawah melalui analisis citra satelit. Informatika pertanian, 15, pp. 853-869.

Wilhelmi, O. V and Wilhite, D. A. (2002). Assessing Vulnerability to Agricultural Drought: A Nebraska Case Study. Natural Hazards. Springer Nature, 25(1), pp. 37-58. [Crossref]

Zin, W. Z. W., Jemain, A. A. and Ibrahim, K. (2012). Analysis of drought condition and risk in Peninsular Malaysia using Standardised Precipitation Index. Theoretical and Applied Climatology. Springer Nature, 111(3-4), pp. 559-568. [Crossref]

Zolotokrylin, A. N. (2010). DROUGHTS: CAUSES, DISTRIBUTION AND CONSEQUENCES. Natural DisastersVolume I. EOLSS Publications, p. 239. 